\title{
«Entre sustos y alegrías»: Noticias y rumores en las fronteras amazónicas durante la Guerra Fantástica (1762-1763)*
}

\author{
«Between fear and joy»: \\ News and Rumors in the Amazon Frontiers \\ During the Guerra Fantástica (1762-1763)
}

\author{
Pablo Ibáñez-Bonillo \\ ORCID iD: https://orcid.org/0000-0003-0874-9350 \\ CHAM / Universidade Nova de Lisboa, Portugal
}

Este artículo analiza la circulación de noticias sobre la guerra entre España y Portugal en las fronteras amazónicas, enfatizando la intervención de los actores locales y su conexión con los acontecimientos globales. Se analizan para ello fuentes primarias de varios archivos iberoamericanos, estudiando el envío de órdenes reales desde las capitales imperiales; los circuitos comunicativos al interior de las provincias americanas; la circulación de gacetas y correspondencia privada, así como las prácticas comunicativas en las posiciones de vanguardia.

Palabras Clave: Frontera; Amazonía; Guerra de los Siete Años; Brasil; comunicación; circulación; noticias.

This article analyzes the circulation of news concerning the war between Spain and Portugal in the Amazon frontiers, emphasizing the agency of local actors and their proximity to global events. This article relies upon the analysis of primary sources from several Iberoamerican archives. The text follows the transmission of royal orders from the imperial capitals; communication circuits at the interior of the American provinces; the circulation of gazettes and private correspondences, and the communicative practices at the furthest outposts.

KeYwords: Frontier; Amazon; Seven Years' War; Brazil; Communication; Circulation; News.

Copyright: (C) 2021 CSIC. Este es un artículo de acceso abierto distribuido bajo los términos de la licencia de uso y distribución Creative Commons Reconocimiento 4.0 Internacional (CC BY 4.0).

* Este trabalho é financiado por fundos nacionais através da FCT - Fundação para a Ciência e a Tecnologia, I.P., no âmbito da Norma Transitória - DL 57/2016/CP1453/CT0094, Portugal. 


\section{Introducción ${ }^{1}$}

A principios de 1762 era ya evidente que el rey de Portugal no podría sortear su participación en la Guerra de los Siete Años (1756-1763), que enfrentaba a las principales potencias europeas y, entre ellas, a Francia e Inglaterra. Aunque la corona lusa se había mantenido neutral en aquel conflicto, disminuido como estaba su poder tras el terremoto que destruyó Lisboa en 1755, José I se veía finalmente en la obligación de tomar partido. Carlos III, nuevo rey de España, había modificado la política de su predecesor y en agosto de 1761 firmó un nuevo Pacto de Familia con los Borbones franceses. Ya en marzo de 1762 intentó atraer al rey de Portugal a dicho pacto, instándole por vía de ultimátum a sumarse a la alianza y, por tanto, a posicionarse en contra de Inglaterra. Rechazada la propuesta en el mes de abril, Portugal y España acabaron entrando en guerra, garantizando Inglaterra su apoyo a la corte lusa. ${ }^{2}$

Los ecos de estas negociaciones diplomáticas llegaron a territorio sudamericano, donde una eventual guerra entre las dos coronas ibéricas colocaba en tensión a todas las unidades administrativas. Las vastas fronteras entre la América española y portuguesa continuaban siendo, en gran medida, territorio disputado, lo que alimentaba los temores de invasiones recíprocas. La falta de una delimitación de dichas fronteras, de hecho, venía generando tensiones a lo largo del siglo XVIII y el Tratado de Madrid (1750) no había conseguido remediar la situación. Dicho tratado preveía la delimitación de las fronteras a partir de la actividad de unas comisiones mixtas de demarcación, pero su ejecución fue solo parcial. Entre desconfianzas mutuas, el tratado fue finalmente anulado con la firma de un nuevo acuerdo en El Pardo (1761), ya en vísperas del conflicto bélico.

Los súbditos americanos, por tanto, estaban especialmente atentos a lo que ocurría en Europa. Estaban expuestos, no en vano, a una doble amenaza. Por un lado, las posesiones ibéricas americanas podían ser objeto de ataques por parte de los principales contendientes de la guerra europea, esto es, Francia e Inglaterra. Tras la firma del Tercer Pacto de Familia, España entró en guerra contra Inglaterra y se pasaron las órdenes oportunas para proteger la América española. Episodios como la toma inglesa de La Habana en agosto de 1762 demostraron que cualquier puerto americano podía ser

1 El autor desea agradecer los comentarios de Carmen Espejo Cala y Juan Marchena Fernández.

2 Barrento, 2006. Téllez Alarcia, 2009. Speelman, 2012. Melón Jiménez, 2016. Marchena, 2018. García Arenas, 2020. 
escenario de la guerra. Además de esta exposición global, las fronteras interiores del continente fueron también territorios de potenciales agresiones entre las dos coronas ibéricas a partir del mes de mayo de 1762, cuando se inició una invasión española del territorio portugués en la península ibérica. Esta ofensiva peninsular, sin embargo, fue un fracaso y estuvo caracterizada por la ausencia de grandes combates.

La situación no fue muy diferente en territorio amazónico y, de hecho, podemos elaborar el paralelismo. ${ }^{3}$ Cuando los soldados españoles entraron en territorio portugués por Trás-os-Montes encontraron pocas tropas enemigas, un ardiente clima y pueblos abandonados, ya que su enemigo optó por una forma de combate marcada por las emboscadas, las guerrillas campesinas y el desabastecimiento de los invasores. Esta ausencia de batallas de importancia llevó a la historiografía portuguesa a referirse a esta fallida invasión como la Guerra Fantástica ${ }^{4}$ Pues bien, en la Amazonía también se frustró una invasión (antes incluso de acometerla) y los contendientes se enfrentaron en un juego de alta tensión, marcado por el clima tropical, la ausencia de movimientos y la dificultad para mantener los canales de suministros. Ambas coronas actuaron con extrema cautela en sus fronteras, registrándose los únicos intercambios de disparos a orillas del río Guaporé, donde la guerra sí dejó muertos, heridos y prisioneros. En el resto de las fronteras amazónicas se vivió más bien en una atmósfera de recelos y preparativos, donde las noticias y rumores sobre el conflicto resultaban fundamentales.

La comunicación entre las cortes ibéricas y las provincias americanas, por tanto, fue en esta época de una importancia trascendental, así como la circulación de noticias sobre la guerra. El presente artículo pretende analizar el impacto de estas comunicaciones y sus variadas formas en el marco de las fronteras amazónicas durante la guerra. Se defiende en este texto que la circulación de noticias y rumores jugó un papel esencial en el desarrollo de la contienda en las principales ciudades americanas, pero también en las remotas fronteras interiores, donde agentes múltiples reconocieron las oportunidades que aquella guerra les ofrecía. El control de la información, de esta manera, fue competido por los distintos actores en pos de objetivos diversos y a través de estrategias también variadas. Modalidades todas de suma importancia en una época donde la transmisión de informaciones (ya

3 Sobre el conflicto en las fronteras amazónicas, véase Gómez González, 2014, 255-266; Brito, 2016, 151-267.

4 Marchena, 2018, 420. 
fuera de forma oral, escrita o impresa) se consolidaba como una herramienta de uso político, tanto en la conformación y gestión de redes de influencia, como en la modulación de las narrativas oficiales.

El análisis de estas distintas escalas de comunicación ha sido posible gracias a la consulta de fuentes primarias en varios archivos ibéricos y latinoamericanos que recogen la documentación oficial de la época, así como de algunas crónicas publicadas posteriormente. Se ha procurado en dichas fuentes cualquier indicio sobre la emisión y recepción de noticias sobre la guerra, entendiendo estas transmisiones de información como parte de estrategias políticas (individuales y colectivas) ancladas en la inmediatez del conflicto bélico. No nos interesa aquí reflexionar sobre la existencia de una opinión pública autónoma y con espíritu crítico ${ }^{5}$ en las fronteras amazónicas. Tampoco se pone el foco en la estrecha relación entre las noticias y la economía, ni en las estrategias de representación del poder regio. ${ }^{6}$

Se trata más bien de analizar las distintas relaciones comunicacionales detectadas en las fronteras durante la guerra, usando la información como herramienta para estudiar los intereses y estrategias de los actores locales. El énfasis en dichos actores, con sus distintos perfiles étnicos y lingüísticos, permite visibilizar las dinámicas propias de los espacios fronterizos, los cuales han sido objeto de estudio recurrente para los historiadores de la América colonial en los últimos años. ${ }^{7}$ Entre los múltiples temas tratados en las investigaciones más recientes, dos aspectos son especialmente relevantes para este artículo: por un lado, la complicada relación de las sociedades de frontera con los poderes metropolitanos y su capacidad para resistir imposiciones y «negociar sus lealtades» $;{ }^{8}$ por otro, la existencia de complejas interacciones sociales al interior de las zonas de frontera, donde el intercambio pacífico y el conflicto conviven en la búsqueda de escenarios de convivencia, ya sea a través de la dominación o de espacios comunes de entendimiento.

Con ese fin, se realiza en primer lugar una aproximación contextual a la geografía física y política sudamericana de la época, analizando la circulación de cartas y órdenes reales desde las capitales imperiales a las principales ciudades coloniales. Se abordan a continuación los circuitos

5 Habermas, 1981 [1962]. Olivari, 2014.

6 Bouza, 1998.

7 Por ejemplo, Boccara, 2005; Langfur, 2006; Herzog, 2018; Levin Rojo y Radding, 2019; Erbig, 2020.

8 La expresión está tomada de Lopes de Carvalho, 2014. 
comunicativos al interior de las provincias americanas, con término en las regiones amazónicas de frontera. Posteriormente, se analiza la circulación de gacetas y correspondencia privada, para estudiar, finalmente, las prácticas comunicativas de los actores anclados en las posiciones de vanguardia. En conjunto, el artículo muestra las estrategias empleadas para el uso de la información por parte de los actores locales. ${ }^{9}$ Este abordaje es especialmente útil para entender, mediante diferentes escalas de análisis, cómo viajaron las noticias sobre la guerra y cómo se alteraron en el proceso. ${ }^{10}$

\section{La comunicación de las coronas con sus capitales de ultramar}

Los primeros avisos sobre la guerra en Europa llegaron a América ya en el año 1755. Francisco Xavier de Mendonça Furtado, gobernador del Grão-Pará, pensaba que la guerra entre franceses e ingleses no les perjudicaría, «em quanto elles se quebram as cabeças, huns aos outros». ${ }^{11}$ Para entonces parecía poco probable la implicación portuguesa en el conflicto. Quizás las autoridades de la América española tuvieron pensamientos similares, aunque progresivamente fue siendo más clara la posibilidad de que ambas coronas se vieran implicadas en la contienda. Ya en diciembre de 1761 se emitía en España un real orden comunicando «el rompimiento con los ingleses, hasta el caso de salir de nuestra corte el embajador británico, y de mandar S. M. retirar al suyo de Londres». ${ }^{12}$ En enero de 1762 se publicaba en Madrid «la Guerra contra el Rey Británico, sus Reynos, Estados y Súbditos, mandando, que desde ahora en adelante no comercien los vasallos de S. M. con los de Inglaterra». ${ }^{13}$ Por otra real orden de 22 de enero se avisaba al virrey del Perú de la guerra con los ingleses y ya en febrero se le informaba de la flota que estos preparaban para enviar a los Mares del Sur. ${ }^{14}$

9 Para un sugerente estudio sobre la circulación de información y desinformación en otra sociedad colonial americana, véase Earle, 1997.

10 Espejo Cala, 2015. Devivo, 2019.

11 Mendonça Furtado para Carvalho e Melo, Mariuá, 22 de noviembre de 1755, Arquivo Histórico Ultramarino, Lisboa (AHU), Conselho Ultramarino (CU), Papéis avulsos da capitania do Pará (13), c. 39, d. 3690.

12 Elexpuru, 1763, 1.

13 Marqués de Esquilache, Madrid, 19 de enero de 1762, Biblioteca Nacional de Perú, Lima, Papeles Varios, XDCH 00171, d. 24

14 Manuel Amat y Junyent, «Relación de Gobierno que hace el Excmo. Sr. Dn. Manuel Amat y Juñyent, Virrey que fue de estos reynos del Perú, y Chile a su sucesor, el Excmo. Sr. Dn. Manuel de Guirior desde 12 de octubre de 1761 hasta 17 de julio de 1776», Capítulo 3. « «Real Sala de Armas, con razón de las que existen», en Amat, 1947, 733. 
Las comunicaciones entre la corte y la América española no eran sencillas en aquella época y los avisos demoraron en llegar a su destino. El 15 de marzo informaba Pedro Messía de la Cerda, virrey del Nuevo Reino de Granada, haber tomado las prevenciones necesarias tras «haberse verificado el anuncio de rompimiento con los ingleses». ${ }^{15}$ En Lima, el virrey Amat tomó prevenciones en mayo para proteger el virreinato peruano y, ya con la guerra confirmada contra Portugal, ordenó concentrar en Cuzco a los súbditos de Inglaterra y Portugal que se «hallasen esparcidos en el Distrito, principalmente en esta Capital». ${ }^{16} \mathrm{Se}$ remitieron auxilios a presidios y puertos, incluyendo Buenos Aires, «donde se hallaban más contiguos los enemigos Portugueses aliados de la Inglaterra, a cuya sombra han cometido y cometen varios excesos y atrevimientos»; y a los gobernadores de Tucumán y Paraguay se les pidió extremar el celo para «impedir cualesquiera hostilidades que pudieran practicar los Portugueses». ${ }^{17}$

La gestión de las fronteras dependía, por tanto, de las distintas audiencias y gobernaciones del virreinato. En la selva central del Perú no era necesario tomar demasiadas precauciones, ya que no había noticias de soldados portugueses en aquellas latitudes, afectadas además por la reciente rebelión indígena liderada por Juan Santos Atahualpa. Más al sur, ya a medio camino entre Lima y Buenos Aires, la audiencia de La Plata (Charcas) velaba por la conservación de las misiones jesuíticas de Mojos y Chiquitos, amenazadas por el progresivo establecimiento de los portugueses en la margen oriental del río Guaporé. Era evidente, además, que aquel avance portugués, que culminó con la fundación del presidio de Nossa Senhora da Conceição en 1760, no solo amenazaba a las misiones, sino también a las preciadas minas de Potosí. ${ }^{18}$ Así, en noviembre de 1762, tras «haberse promulgado bando en Los Reyes [...] declarando la guerra al Rey de Portugal y sus vasallos», el virrey Amat escogió al presidente de la audiencia de La Plata, Juan de Pestaña, para comandar una expedición de desalojo. ${ }^{19}$ Esta

15 Pedro Messía de la Cerda a Julián de Arriaga, Santa Fe, 15 de marzo de 1762, Archivo General de Indias, Sevilla (AGI), Santa Fe, 576.

16 Elexpuru, 1763, 1 y 17.

17 Manuel Amat y Junyent, «Relación de Gobierno... », Capítulo 2. ${ }^{\circ}$ «Preparativos y disposiciones militares con ocasión de la guerra declarada con Yngleses y Portugueses, año de 1761», en Amat, $1947,712$. $835-836$.

18 Ceballos a Arriaga, 3 de agosto de 1761, AGI, Buenos Aires, 537; en Pastells, 1949,

19 Resumen de carta del virrey Amat a Juan de Pestaña, Lima, 28 de noviembre de 1762, AGI, Lima, 1054; Testimonio del Marqués de Salinas, en Pastells, 1949, 998-1015. 
campaña, que finalmente dirigió el gobernador de Santa Cruz, Alonso Verdugo, no tuvo éxito, ${ }^{20}$ como tampoco lo tuvo un posterior intento en 1766.

Las misiones jesuíticas de Maynas, a su vez, entraban en la jurisdicción de la audiencia de Quito y, por tanto, del virreinato del Nuevo Reino de Granada. Pedro Messía de la Cerda era el virrey cuando en 1762 llegaron los avisos de la guerra. ${ }^{21}$ Aunque su residencia se encontraba en la ciudad de Santa Fe, en septiembre de 1762 se trasladó a Cartagena tras recibir noticias del asedio inglés a La Habana, y en prevención de otros ataques posibles en el litoral caribeño. ${ }^{22}$ Hacia el oriente, las fronteras con los portugueses se extendían de manera imprecisa por las regiones meridionales de la provincia de Guayana. La zona de encuentro entre ambas coronas estaba allí en el alto río Negro y el canal de Casiquiare, que conectaba las cuencas de los ríos Amazonas y Orinoco. En este último río se encontraba José de Iturriaga, que había sido designado como primer comisario para las demarcaciones del Tratado de 1750 y que ostentaba el cargo de Comandante General de las Nuevas Poblaciones de Orinoco. ${ }^{23}$

La multiplicidad de agentes implicados en la defensa de las fronteras interiores encontraba réplica en el lado portugués. La sección meridional del territorio amazónico, frontera con las misiones de Mojos, pertenecía a la capitanía de Mato Grosso, fundada en 1748 y con centro en Vila Bela da Santíssima Trinidade. Hasta allí llegaban los suministros desde Rio de Janeiro, Goiás y el puerto de Santos, pero también desde el río Amazonas. Antonio Rolim de Moura, gobernador de Mato Grosso, fue uno de los protagonistas de la guerra en las fronteras amazónicas, conservando las posiciones que los portugueses habían tomado en el río Guaporé en 1760. La tensión era permanente en aquella frontera ya desde antes de la declaración de guerra y esta apenas precipitó un conflicto que se venía gestando desde hacía tiempo. Parece, por lo demás, que las noticias de la guerra llegaron con notable retraso al Mato Grosso. El sargento mayor Francisco Antonio de Anguera y Fiorilo se admiraba de que ya en 1763 aquellos portugueses todavía no supiesen «que El Rey Catho[lico] havia declarado a Guerra, havia hum anno e tantos mezes, a S. Mage F[idelissima], tinha já tomando a maior parte do Reyno». ${ }^{24}$

20 Castilho Pereira, 2017.

21 Arriaga a Messía de la Cerda, 22 de enero de 1762; Madrid, 17 de junio de 1762, AGI, Santa Fe, 575 .

22 Messía de la Cerda a Arriaga, Mompós, 23 de septiembre de 1762, AGI, Santa Fe, 575. 2015.

23 Sobre esta sección de frontera, véase Ramos Pérez, 1946; Lucena Giraldo, 1991; Perera,

24 Citado en Castilho Pereira, 2017, 104. 


\section{MAPA 1}

\section{PRINCIPALES LUGARES MENCIONADOS EN ESTE ARTÍCULO}

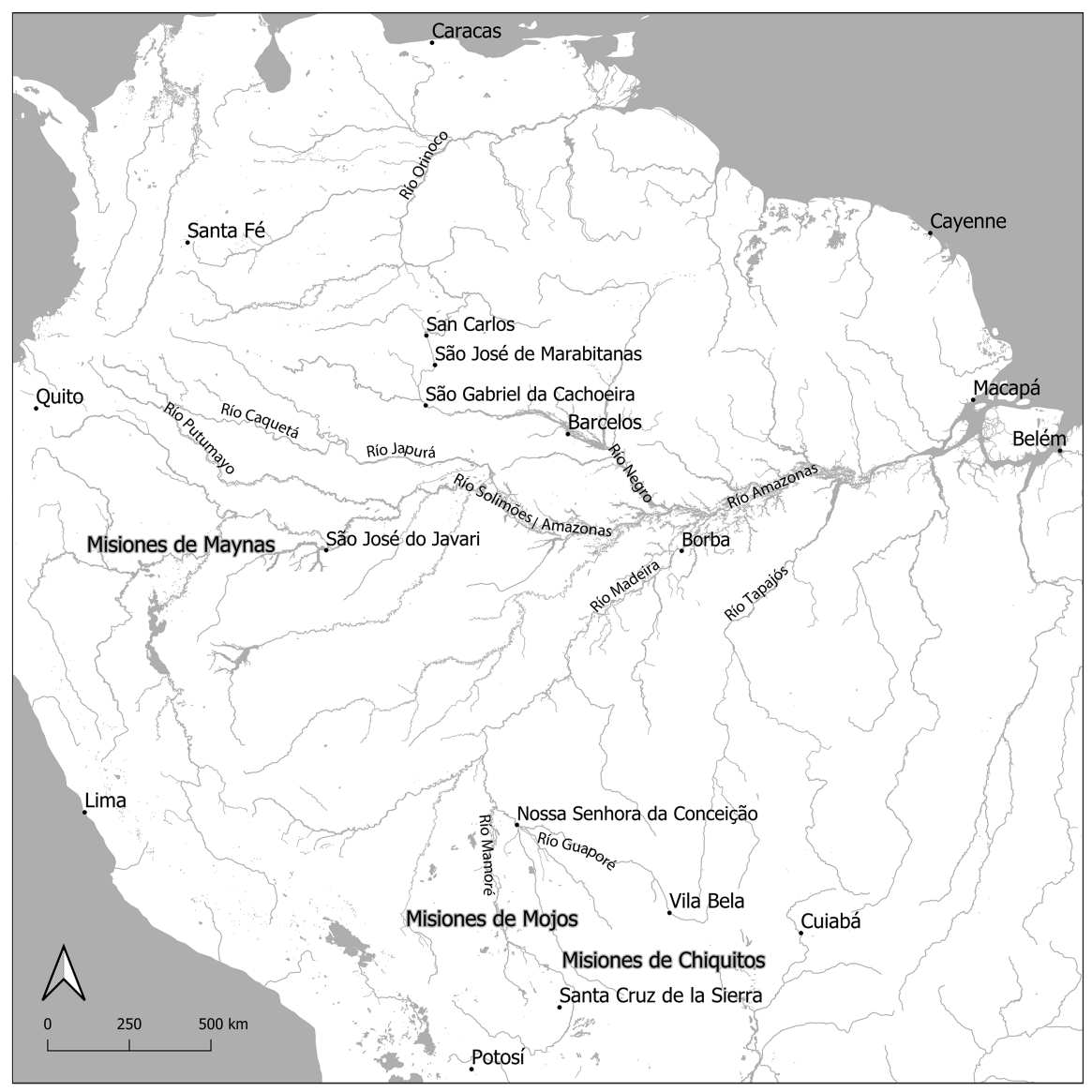

Fuente: Laboratório de História Social, Universidade de Brasília.

El resto de territorio amazónico era controlado por el Estado de Grão-Pará e Maranhão, con capital en la ciudad de Belém. La enormidad de este estado era, en parte, paliada por la existencia de capitanías, siendo la de São José do Rio Negro la que concentraba las regiones de frontera con el imperio español. Esta capitanía había sido fundada en 1755 y tenía en Barcelos su principal enclave. Desde Lisboa se intentó mantener informado 
al gobernador de Grão-Pará, Manuel Bernardo de Melo e Castro, sobre el desarrollo de los acontecimientos en Europa y ya en febrero de 1762 se le enviaron noticias sobre el «quazi declarado rompimento» con las coronas de Francia y Castilla. ${ }^{25}$ A fines de junio, Melo e Castro informaba que se encontraba «trabalhando em defender esta cidade» y asistiendo al resto de lugares de su jurisdicción. ${ }^{26}$ Se mantenía en la región, empero, la esperanza de que el conflicto no llegase hasta América, pues la experiencia mostraba que «não he a primeira vez que havendo guerra na Europa, se conserva a America em armisticio». ${ }^{27}$

\section{Comunicaciones oficiales al interior de las colonias}

Ciudades como Lima, Santa Fe, La Plata o Buenos Aires actuaban como intermediarias para la circulación de órdenes y noticias entre la corte y las regiones interiores. Para comunicar la declaración oficial de guerra, el virrey Amat mandó copias de los bandos promulgados a los corregidores de las villas y lugares principales de cada provincia, junto con «instrucciones y providencias circulares» para disponer de las milicias necesarias. ${ }^{28}$ Se aprovechaba, así, la «estructura político-administrativa que conectaba a la metrópoli con los territorios periféricos» ${ }^{29}$ activando una «cadena de mando encabezada por los virreyes» y de la que también formaban parte audiencias y gobernaciones. Así, el presidente de La Plata comunicaba al secretario de Marina e Indias, Julián de Arriaga, el cumplimiento de la orden para aprehender los bienes de los súbditos de Inglaterra y Portugal, e informaba de la publicación del bando, «que se arregló literalmente al Capítulo de la Gazeta que V. E. se sirvió dirigirme, y se ejecutará sin dilación lo mismo en todo el distrito de esta Gobernación como V. E. me ordena». ${ }^{30}$

En la América portuguesa la transmisión de informaciones seguía una lógica similar, destacando el papel de la ciudad de Belém, conectada a las regiones de frontera gracias a la navegación del sistema fluvial amazónico.

25 Mendonça Furtado al Gobernador de Grão-Pará, 11 de febrero de 1762, AHU, códice 593, carta 195

26 Melo e Castro para Mendonça Furtado, Pará, 28 de junio de 1762, AHU, CU, 13, c. 52, d. 4790 .

27 Lourenço Pereira da Costa para Mendonça Furtado, Barcelos, 2 de septiembre de 1762, AHU, CU, Papéis Avulsos da Capitania do Rio Negro (20), c. 2, d. 112.

28 Elexpuru, 1763, 17.

29 González Cruz, 2019a, 175.

30 Juan de Pestaña a Julián de Arriaga, Plata, 10 de noviembre de 1762, AGI, Charcas, 433. 
De esta manera, a través de canoas y remeros indígenas, la correspondencia oficial fluía entre la capital colonial y los más alejados destacamentos del estado del Grão-Pará, a través de puestos intermedios como Borba (en el río Madeira) o Barcelos (en el río Negro). Ello no evitaba que lo hiciera con mucho retraso, precisándose de varias semanas para viajar de Belém a Barcelos (siendo más corto el viaje en dirección contraria). Las órdenes reales, por tanto, debían atravesar el océano Atlántico y gran parte del Amazonas en un largo viaje antes de llegar a Barcelos, desde donde se redirigían a los destacamentos instalados en lugares como São José do Javari, Castro de Avelãs (río Solimões), Cachoeira Grande (São Gabriel da Cachoeira) o São José dos Marabitenas (río Negro).

Una de las posiciones más débiles en este engranaje comunicativo era la del gobernador de Mato Grosso en el Guaporé, alejado de las principales ciudades. Los españoles creían que podían aislarle y con ese fin planearon acciones para cortar sus comunicaciones con el resto de posiciones lusas. El objetivo último era desalojar a los portugueses o, por lo menos, contener sus avances en aquella frontera. Sin embargo, los portugueses no podían descartar que se estuviese planeando una invasión más ambiciosa por el río Madeira. No había de qué preocuparse, opinaba el veterano João de Souza Azevedo, ya que los españoles no tenían «gente pratica nem povoaçoes suas donde possão ser socorridos» en su navegación por el río. En la misma carta, comentaba las noticias del asedio de Almeida, ocurrido meses antes en la península: «Já V. S. ${ }^{a}$ hé siente que os nossos Portugueses com mil e quinhentos homens na praça de Almeyda se defenderao quatro meses de hum exercito de 30 ou 40 mil homens e fizerao mortandade de sinco mil espanhoes $[\ldots] \gg .{ }^{31}$ Las noticias y rumores sobre la guerra peninsular, pues, se filtraban ya en las conversaciones en 1763.

En la América española, las comunicaciones con las regiones amazónicas eran igualmente complicadas. La cordillera andina suponía un obstáculo para la circulación de cartas y órdenes reales hacia unas regiones que, además, estaban históricamente asociadas con diversos mitos y leyendas. ${ }^{32}$ Así pues, las noticias que los virreyes tuvieron de las fronteras amazónicas fueron siempre menos precisas de lo deseado, diluidas por la lejanía de aquellas tierras. Desde la capital peruana lamentaban, por ejemplo, que la última carta del gobernador Verdugo enviada desde la provincia de Santa

31 João de Souza Azevedo, Río Madeira, 14 de junio de 1763, Arquivo Público do Estado do Pará, Belém do Pará (APEP), códice 133, d. 29.

32 Gil, 1989. 
Cruz había demorado tres meses y medio en llegar a Lima. ${ }^{33}$ Incluso en la ciudad de San Francisco de Quito, más cerca de la frontera, faltaban noticias y sus habitantes creían «que la Nación Portuguesa pretende introducirse en las Colonias, del Gobierno de San Francisco de Borxa y Archidona». ${ }^{34}$

La lentitud de estas comunicaciones provocaba retrasos informativos que venían a sumarse a los ya acumulados por la distancia con Europa. Era tanta la distancia que, de hecho, en América se vivía una «situación irreal, por anacrónica», llegándose a proclamar en Lima la declaración de guerra casi al mismo tiempo que se firmaban en Fontainebleau los preliminares de paz. ${ }^{35}$ Existía así el riesgo de que la noticia de estos acuerdos llegase demasiado tarde a las fronteras americanas, por lo que se enviaron copias de los mismos a las distintas autoridades. El secretario de Marina e Indias, Julián de Arriaga, advertía al virrey del Nuevo Reino de Granada que enviase copia de los preliminares a su homólogo peruano, por si las noticias enviadas por Buenos Aires sufrían algún percance. ${ }^{36}$ Por su parte, el gobernador portugués en Belém envió copias de los acuerdos finales de paz a los comandantes de Macapá y Barcelos, temiendo que los españoles atacasen en la ignorancia de las paces. ${ }^{37} \mathrm{Al}$ sur, el gobernador de Mato Grosso envió a su homólogo de Santa Cruz, en 10 de agosto de 1763, el tratado definitivo de paces, el cual había recibido de «un General de América amigo suyo». ${ }^{38}$ Parece que este «amigo» fue el gobernador de Grão-Pará, Melo e Castro, quien en otro lugar escribiría: «Permitirá Deos que chegue este meio de se evitar a guerra na America, depois que a sua Providencia a fez cessar na Europa». ${ }^{39}$

\section{Los instrumentos de la comunicación: ${ }^{40}$ bandos y gacetas}

Hasta aquí hemos visto cómo la información institucional era apreciada por su capacidad para transmitir instrucciones. Sin embargo, las noticias

33 Traslado del Real Acuerdo, Lima, 13 de septiembre de 1763, AGI, Lima, 1054; en Pastells, 1949, 950-952.

34 Providencia de Manuel Rubio de Arévalo para que los vecinos de Quito declaren y exhiban las armas que poseen, Quito, 16 de febrero de 1763, Archivo Nacional del Ecuador, Quito (ANE), Gobierno, c. 21, exp 9. La relación de armas está transcrita en Gómez González, 2014, 264-265.

35 Durand, 1982b, XIX.

36 Mención al Real Despacho en Testimonio del Marqués de Salinas, f. 10r, AGI, Lima, 1054. Messía de la Cerda a Arriaga, Cartagena, 1 de mayo de 1763, AGI, Santa Fe, 576.

37 Melo e Castro a Mendonça Furtado, Pará, 15 de junio de 1763, AHU, CU, 13, c. 54, d. 4939

38 Rolim de Moura a Alonso Verdugo, Nossa Senhora da Conceição, 1 de septiembre de 1763 , en Pastells, 1949, 940-941.

39 Melo e Castro a Mendonça Furtado, Pará, 28 de junio de 1763, AHU, CU, 13, c. 54, d. 4953.

40 Tomo la expresión del título del capítulo IV de Olivari, 2014, 185-311. 
de guerra tenían también capacidad de generar estados de ánimo en la sociedad, por lo que ambas coronas trataron de controlar la comunicación pública sobre la guerra. La estrategia más sencilla para ese fin era ordenar la publicación de determinadas noticias, como la firma de tratados de paz. ${ }^{41}$ Así ocurrió en marzo de 1763, cuando Carlos III pasó órdenes de publicar el tratado de paz definitivo «para que llegue a noticia de esos mis Vasallos». Recibida la comunicación en Quito, el presidente y los oidores de la audiencia, «estando en pie y destocados», «besaron y pusieron sobre sus cabezas» la carta real, el 19 de septiembre. Un día más tarde, el pregonero público leyó el real escrito en las calles y plazas de Quito, al son de cajas y clarines. ${ }^{42}$ También en Lima se celebraron las paces «por tres días con repiques e iluminaciones», ${ }^{43}$ mientras que en Belém se realizaron tres noches de luminarias para celebrar el final de la contienda. ${ }^{44}$

Los púlpitos fueron otro efectivo foco de emisión, informándose los feligreses a través de los sermones de los párrocos y de las celebraciones. El obispo de Leiria (Portugal), Miguel de Bulhões, que había sido antes obispo de Pará y por lo que debió sentirse especialmente concernido por el devenir de la guerra en los territorios americanos, ordenó «a todos os Ecclesiasticos Seculares, e Regulares, que nas suas Igrejas consagrem a Deos hum solemne Sacrificio de louvor», rematado con un Te Deum Laudamus «em acção de graças pela conclusão de huma Paz, igualmente desejada, e gloriosa». Y «para que chegue á noticia de todos mandamos passar a presente, que será publicada á Estação da Missa, e fixada nas portas de todas as Igrejas do nosso Bispado» ${ }^{45}$ Ceremonias similares se dieron en ciudades como Lima ${ }^{46}$ y, aunque falten las evidencias, quizás también en las fronteras amazónicas.

Publicaciones de bandos, luces y sermones eran, pues, medios efectivos para (in)formar a una sociedad mayoritariamente analfabeta. La letra escrita, sin embargo, tenía también una influencia considerable para las sociedades americanas de mediados del siglo XVIII. Y aunque ni el número de imprentas ni la densidad de las comunidades lectoras podían compararse con las de Europa, lo cual limitaba el impacto de los materiales impresos,

41 González Cruz, 2019b.

42 ANE, Cedulario, c. 13, vol. 1, ff. 65-66 (235-236).

43 Gaceta de Lima, del 7 de septiembre al 8 de noviembre de 1763, Durand, 1982b, 120.

44 Melo e Castro, Pará, 9 de marzo de 1763, AHU, CU, 13, c. 54, d. 4902.

45 Pastoral, 2 de abril de 1763, Biblioteca Nacional de Portugal, Lisboa (BNP), Impressos Reservados, RES. 4243//13v.

46 Gaceta de Lima, del 7 de septiembre al 8 de noviembre de 1763, Durand, 1982b, 120. 
sí circulaban noticias publicadas en variadas formas. ${ }^{47}$ Papeletas sueltas y pasquines permitían una difusión rápida de noticias inesperadas, como el terremoto que en 1755 destruyó la ciudad de Lisboa. Las noticias de este suceso, que también afectó a las ciudades de Cádiz y Sevilla, llegaron a la América española «escritas en diversas Papeletas». ${ }^{48} \mathrm{La}$ fluidez informativa, por otra parte, no era unidireccional: unos años antes, se imprimía en Lisboa una Notícia verdadeira do terrível contágio... que venía azotando a la Amazonía lusa. ${ }^{49}$

Existía, por tanto, una tradición de comunicar acontecimientos a través de impresos y las coronas conocían la potencialidad de esos canales. No es de extrañar, en este contexto, que la propaganda y la comunicación de masas jugasen un papel fundamental en el desarrollo de la Guerra de los Siete Años y, específicamente, en el conflicto ibérico que aquí estamos presentando. Así, los franceses exageraron la importancia de las victorias españolas en territorio portugués a través de grabados y narraciones, convirtiendo la toma de Salvaterra do Extremo, por ejemplo, en una gesta que poco tenía que ver con la realidad. ${ }^{50}$ Por su parte, en el bando opuesto también se echó mano de la comunicación de masas, con objetivos similares. Poco después de la toma de La Habana, se imprimió en Lisboa la traducción de una gaceta inglesa que informaba de los acontecimientos, incluyendo un mapa y detalles de lo ocurrido. ${ }^{51}$

La influencia de estas gacetas no se limitó a los territorios peninsulares. El presidente de La Plata recibió «las Gazetas que dan noticia de las ventajas conseguidas por nuestro ejército en el Reino de Portugal». ${ }^{52} \mathrm{Y}$ el comandante de Macapá recibió en su puesto fronterizo una gaceta con la crónica del episodio habanero. ${ }^{53}$ Se la había entregado el director de una villa cercana, cumpliendo órdenes del gobernador del Grão-Pará. Eso nos da una pista sobre la intricada relación entre el poder político y el uso de la información, puesto que la difusión de este tipo de gacetas parece haber servido para orientar las decisiones de las autoridades en las regiones de

47 Como en el caso de Nueva Granada, estudiado en Earle, 1997.

48 Gaceta de Lima, del 20 de abril al 9 de junio de 1756, Durand, 1982a, 14.

49 Noticia verdadeyra do terrivel contagio, que desde outubro de 1748 ate o mez de mayo de 1749 tem reduzido a notavel consternaçã̃ todos os certões, terras, e cidade de Bellém, e Grã̃ Pará, extrahida das mais fidedignas memorias, BNP, Impressos Reservados, RES. 1343//12 P.

50 Marchena, 2018, 420. García Arenas, 2020.

51 Gazeta Extraordinaria de Londres, 30 de septiembre de 1762, BNP, Impressos Reservados, RES. $4243 / / 2 \mathrm{~V}$.

52 Juan de Pestaña a Julián de Arriaga, La Plata, 10 de noviembre de 1762, AGI, Charcas, 433.

53 Nuno da Cunha para el Gobernador, Macapá, 27 de abril de 1763, APEP, códice 132, d. 34. 
frontera. Queda la duda sobre su influencia en el resto de habitantes de la Amazonía, espacio en el que faltaban algunas de las instituciones que contribuyen a la existencia de una opinión pública. ${ }^{54}$ Así, aunque existieran ciertos espacios de socialización de las noticias, faltaban otros como universidades o periódicos locales.

Elementos estos que sí se encontraban en las grandes ciudades de la América española, específicamente en Lima, donde existía una iniciativa informativa local. La Gaceta de Lima acompañó desde el principio los acontecimientos de la Guerra de los Siete Años y ya en el número del mes de mayo de 1762 publicó el rompimiento entre España e Inglaterra. ${ }^{55}$ En diciembre informó sobre la firma del pacto de familia, las victorias en la invasión peninsular de Portugal y los ataques ingleses en La Habana. En el número siguiente se apuntó que, según cartas de sujetos autorizados de Guayaquil, «los Ingleses habían levantado el Sitio de la Habana el día 10 de Agosto del año pasado, con pérdida considerable de su Tropa y Navíos». ${ }^{56}$ Lo cierto, sin embargo, es que los ingleses tomaron la ciudad el 14 de agosto de 1762 y en marzo del año siguiente La Gaceta todavía no podía «dar con certeza los imaginados acaecimientos de La Habana, que tanto han inquietado los ánimos, por lo importante de su materia». ${ }^{57}$

En la misma línea, parece que La Gaceta no dio cuenta de una campaña mucho más cercana: la fallida expulsión de los portugueses del Guaporé, de la que no hemos encontrado noticias en los ejemplares consultados hasta diciembre de 1765 . Aunque es cierto que La Gaceta limeña dedicaba poca atención a otras regiones del virreinato, este silencio informativo contrasta con la cobertura dada a episodios como la captura española de Colonia del Sacramento. ${ }^{58}$ Esto tal vez denote la parcialidad de aquel periódico, auspiciado por el virrey Amat y dirigido por su propio médico de cámara, Isidro José Ortega y Pimentel, desde septiembre de $1762 .{ }^{59}$ La Gaceta era «la voz del consensus y de los valores deseados dentro de los grupos dominantes», ${ }^{60}$

54 Earle, 1997, 183. Olivari, 2014, 99-184.

55 Gaceta de Lima, del 2 de abril al 13 de mayo de 1762, Durand, 1982a, 350.

56 Gaceta de Lima, del 10 de octubre al 3 de diciembre de 1762. Durand, 1982b, 9-14; Gaceta de Lima, del 3 de diciembre de 1762 al 20 de enero de 1763, Durand, 1982b, 33.

57 Gaceta de Lima, del 20 de enero al 30 de marzo de 1763, Durand, 1982b, 41.

58 Gaceta de Lima, del 3 de diciembre de 1762 al 20 de enero de 1763, Durand, 1982b, 30-33; Gaceta de Lima, del 30 de marzo al 20 de mayo de 1763, Durand, 1982b, 58-61; Gaceta de Lima, del 12 de julio al 7 de septiembre de 1763, Durand, 1982b, 92-97.

59 Durand, 1982b, XV y XXIV.

60 Herzog, 1992, 51. 
y tan importante era lo que decía «como algunos puntos que calla». ${ }^{61} \mathrm{En}$ palabras de González Cruz, que también ha analizado el contenido de la $G a$ ceta en estos años, los periódicos americanos «se constituyeron en referentes del discurso oficial», en «soportes propagandísticos» especialmente útiles en tiempos de guerra. ${ }^{62}$

Existía, por tanto, una clara conciencia del impacto social que las noticias podían generar en las audiencias de aquella época. Así, desde Lisboa, ante la inminencia de la guerra, se ordenó al gobernador de Grão-Pará que tomase precauciones, pero previniéndole que «por hora, nem deve dar-se por entendido do estado em que se acham as cousas da Europa nem deixar transpirar a esse Povo o que passa». ${ }^{63}$ Para justificar las precauciones, debía pretextar que servirían para «fazer observar a neutralidade de El Rey Nosso Senhor» en la «guerra declarada entre França, Castella e Inglaterra». No en vano, como le recordaba el gobernador de Rio Negro a Mendonça Furtado en otro contexto, «ninguem sabe melhor do que Vossa Excelencia as angustias que se padese neste sertão quando a elle chegão noticias infaustas desse Reyno». ${ }^{64}$ El silencio oficial permitía controlar el flujo de noticias y ostentar cierto monopolio informativo, pero la sociedad se mantenía conectada a la actualidad a través de otros canales, como las correspondencias privadas.

\section{Correspondencias privadas}

Las órdenes religiosas, por ejemplo, contaban con sus propias redes comunicacionales en forma de correspondencia. A nivel local, los superiores podían escribir cartas circulares para los distintos misioneros, como parece haber ocurrido en el sistema misional de Mojos. ${ }^{65}$ En dirección contraria, los misioneros podían enviar a sus superiores noticias (o la ausencia de ellas) sobre avistamientos e intercambios con los portugueses. ${ }^{66}$ También enviaban y recibían cartas de sus familias en Europa. El misionero Uriarte

61 Durand, 1982a, XXII.

62 González Cruz, 2011, 364 y 383.

63 Para el gobernador de Grão-Pará, 11 de febrero de 1762, AHU, códice 593, carta 195.

64 Se refería a las noticias del terremoto de 1755, que Mendonça Furtado recibió en América. Joaquim de Melo e Povoas a Mendonça Furtado, Barcelos, 18 de agosto de 1760, AHU, CU, 20, c. 1, d. 70

65 Rolim de Moura a Mendonça Furtado, Nossa Senhora de Conceição, 1 de junio de 1763, AHU, CU, 10, c. 12, d. 692.

66 Manuel Uriarte a Jerónimo Herce, 27 de febrero de 1762, Biblioteca Ecuatoriana Aurelio Espinosa Pólit de Quito, Quito, leg. XIV, d. 1287. 
escribía a su hermano en España y este le informaba de acontecimientos como la entrada de Carlos III en Zaragoza o la persecución que sufrían los jesuitas en Francia.$^{67}$ De hecho, es posible que a Uriarte y a sus compañeros les preocupase más en aquellos días el incierto futuro de la Compañía que los efectos de la guerra en las fronteras amazónicas. Sabían que su posición intermediaria en la frontera incomodaba a los administradores de ambas coronas, los cuales recelaban de su fidelidad. ${ }^{68}$

Esta delicada posición de los jesuitas favorecía cierta solidaridad entre los miembros de la Compañía a los dos lados de la frontera, como la que mantuvieron los misioneros de Maynas y los que actuaban en el río Javari. Las autoridades lusas eran conscientes del riesgo que suponían estas comunicaciones y de la necesidad de interrumpirlas. ${ }^{69}$ Cuando finalmente los jesuitas fueron desalojados de aquella frontera, los religiosos Manoel dos Santos y Luis Gomes opusieron alguna resistencia, llegando «a praticar os índios que fugissem, não só para irem com eles para baixo, mas até para irem para as aldeias de Castela». ${ }^{70}$ Muchos así lo hicieron y con ellos desertó un soldado portando una carta en la que el misionero portugués explicaba las novedades a los misioneros de Maynas. «También llegó otra carta del Rector del Pará, en que decía iban desterrados a Lisboa dieciséis jesuitas, y él entre ellos, con un Padre Roque, alemán, insigne Misionero». ${ }^{71}$ Se refiere aquí a Roque Hunderpfundt, expulsado del Pará con la acusación de participar en un plan de sedición.

Entre los jesuitas expulsados con Hunderpfundt se encontraba Antonio José, quien había sido responsable de la misión de Trocano, en el río Madeira, rebautizada luego como villa de Borba. Tras su expulsión, el misionero mantuvo algún contacto con la villa, tal y como sugiere la copia de una carta que le escribió al capitán Diogo Antonio de Castro. En la misiva, fechada años antes de la declaración de guerra, Antonio José informaba que «estão em Badajos alojados vinte Regimentos de Castella, e vão-se ajuntando mais, dizem que para nos socorrer no que for precizo, querem

67 Negro, 2007, 97-98. Uriarte, 1986, 306.

68 Rolim de Moura a Alonso Verdugo, Vila Bela, 25 de octubre de 1760, AGI, Charcas, 433; en Pastells, 1949, 723-736.

69 Sebastião José de Carvalho e Melo a Mendonça Furtado, Lisboa, 17 de marzo de 1755, Biblioteca de Ajuda, Lisboa, 54-XI-27, N. 16, f. 20r. Para el caso específico del Guaporé: Mendonça Furtado a Corte Real, Pará, 29 de octubre de 1757, APEP, códice 93, d. 10. 112-118.

70 Mendonça Furtado a Carvalho e Melo, Mariuá, 12 de octubre de 1756, en Mendonça, 2005,

71 Uriarte, 1986, 241. 
dizer que contra França». Añadía que «se as guerras de França forem certas, paresseme que Portugal não será o alvo dos Francezes»; más bien estarían las posiciones americanas en el punto de mira, ya que «não faltará que ver a América como parte que lhes poderá dar mais lucro e proveito». ${ }^{72}$

La importancia de estas correspondencias privadas, por tanto, trascendía las estructuras de las órdenes misioneras. Otras redes de interés y afectos mantenían un flujo permanente de comunicación, donde estaban presentes las informaciones sobre el devenir de la guerra. Encontramos un ejemplo de estas epístolas en la correspondencia entre João Pereira de Caldas (futuro gobernador del Grão-Pará y que en 1762 servía como gobernador de Piauí) y su «tío» João de Almada, de la que solo conocemos una carta. ${ }^{73} \mathrm{El}$ intercambio tal vez se iniciara en julio de 1762, fecha en la que Pereira de Caldas escribió desde Piauí informando a Almada de algunos problemas de salud. Esta carta es mencionada en otra de diciembre del mismo año, que sirve como respuesta. Tras desearle una mejora de salud, Almada comparte desde Porto (Portugal) las últimas noticias de la guerra tras la firma de los preliminares de paz, «tendo Castella arruinado hum exercito de cincoenta mil homens em marchas e contramarchas e choques». ${ }^{74}$

Es también interesante la carta que Pereira Caldas recibió de José Gomes Ribeiro, fechada en febrero de 1763. Escribiendo desde la villa de Cachoeira (en Bahia, Brasil), el autor le informaba de varias novedades sobre la guerra, como la fallida invasión peninsular y la firma de los armisticios. ${ }^{75}$ Gomes Ribeiro parece haber sido paisano de Pereira de Caldas, puesto que también le comenta con satisfacción que «[n]a nossa Provincia donde tive varias cartas, não tinha havido hostilidade alguma dos inimigos, e se tinha Deos lembrado dos seus habitantes com a copiosa abundancia de frutos, que em tempo tal, he o beneficio mayor, que lhe podia permetir». La preocupación con las provincias de origen tenía que ver con la salud de los parientes, pero también con las posibles pérdidas en los patrimonios familiares, como los intereses que el gobernador de Grão-Pará, Melo e Castro, tenía en el Alentejo. ${ }^{76} \mathrm{La}$ intimidad de esta correspondencia abarcaba también los vínculos de parentesco, pues el autor comenta la promoción de João de

\footnotetext{
72 Antonio José a Diogo Antonio de Castro, 23 de abril de 1757, AHU, CU, 20, c. 1, d. 51. 2010 .

73 Sobre la figura de Pereira de Caldas y su relación con la familia Almada, véase Santos,

74 João de Almada a Pereira de Caldas, Porto, 7 de diciembre de 1762, APEP, códice 127, d. 1. d. 2 .

75 José Gomes Ribeiro a Pereira Caldas, Cachoeira, 26 de febrero de 1763, APEP, códice 127,

76 Melo e Castro a Mendonça Furtado, Pará, 21 de julio de 1762, AHU, CU, 13, c. 52, d. 4812.
} 
Almada a teniente general de los Ejércitos, con la patente de consejero de Guerra. Finalizaba con expectativas de más noticias: «Esperasse a Nau do Tabaco, como tambem o resto da Frotta, que ficou em Lisboa, e a certeza de se ter concluido, e asignado nas cortes biligirantes os artigos da Paz Geral, que Deos queira se tenha efectuado para bem universal de toda a Europa».

Con estas cartas en la mano, João Pereira de Caldas escribió al gobernador del Grão-Pará, haciéndole partícipe de las noticias que había acumulado e incluyendo copias de las dos citadas cartas. Además, le comentaba otras noticias de la guerra, como la pérdida de Colonia del Sacramento o la toma de La Habana por parte de los ingleses, una pérdida que «não deixará de ser sumamente sensível aos mesmos Espanhoes», y que estaba referida en una «gazeta extraordinaria publicada em Londres, e impressa em Lisboa, em Portuguez», seguramente la misma gaceta que ya hemos mencionado en este artículo. También se hacía eco de rumores sobre la presencia de ingleses en Portugal, entre los que se encontraría hasta un hermano de la misma reina. Noticias y rumores que se fundían en un afán patriótico: «O nosso exercito he formidavel, de forma que nunca em Portugal houve tão poderoso». ${ }^{77}$

\section{Comunicaciones entre súbditos de ambas coronas}

Además de esta correspondencia entre vasallos de una misma corona, existían también intercambios de misivas entre los súbditos de las monarquías Católica y Fidelísima. El misionero español de San Joaquín, en el río Putumayo, tenía tratos con varios portugueses que le suministraban productos para su misión. Estas transacciones dejaban huella en cartas como la que el gobernador de Maynas, Antonio de la Peña, envió al vicario de la villa de Olivença, pidiéndole una serie de productos para él mismo y para los misioneros jesuitas. ${ }^{78}$ Existían pues intercambios fluidos entre las dos Américas por aquellas fronteras y el contrabando resultaba habitual. ${ }^{79}$ Esta comunicación, sin embargo, cambió con el anuncio de la guerra. Así, ante el decreto real de prohibir «toda a correspondençia e comunicassão» con

d. 7 .

77 Pereira Caldas a Melo e Castro, Oeyras do Piahuy, 28 de abril de 1763, APEP, códice 127,

78 Antonio de la Peña a João de São Jerónimo, San Ignacio de Pebas, 21 de abril de 1765, APEP, códice 29, d. 32.

79 Gómez González, 2014. Brito, 2016. Bastos, 2017. 
españoles y franceses, el misionero del Putumayo fue temporalmente privado del contacto con indígenas y portugueses. ${ }^{80}$

Más rastro documental dejó la comunicación entre los oficiales destinados a los puestos fronterizos, especialmente en los ríos Negro y Guaporé (o Itenez). En 1759, el gobernador de Santa Cruz de la Sierra, Alonso Verdugo, informaba «que el Procurador de las Misiones de Moxos havía visto una canoita con un Portugués, y tres Negros que parece iban reconociendo las entradas del Rio grande». En respuesta, se ordenó redoblar la atención, «por si traían algunas cartas relativas al tratado de Límites». ${ }^{81}$ En lugar de cartas, los portugueses trajeron hombres y pertrechos para ocupar en febrero de 1760 la misión de Santa Rosa (la Vieja), que los jesuitas habían desalojado algún tiempo atrás. Las relaciones desde entonces entre los agentes de las dos coronas no fueron sencillas, tal y como se desprende del intenso intercambio de cartas entre el gobernador portugués de Mato Grosso, los jesuitas de Mojos y el gobernador de Santa Cruz de la Sierra. ${ }^{82}$

Este tipo de cartas servía como canal de comunicación y, llegado el caso, como medio para plantear amenazas y ultimátums. También era el soporte para futuras quejas o reivindicaciones ante las cortes europeas. Los oficiales tenían mucho cuidado en lo que escribían y ponían cuidado también en archivar y remitir a sus superiores las cartas que recibían, a fin de exculparse en situaciones futuras. ${ }^{83}$ Esto no resultaba sencillo, ya que las cartas podían perderse, mojarse y destruirse, provocando el fracaso de la comunicación pretendida, como ocurrió con una carta que el gobernador Melo e Castro dirigió desde el Pará a Iturriaga ${ }^{84}$ Por otra parte, cuando faltaba el papel en la frontera podía llegar a ser preciso viajar en persona para asegurarse de que las noticias llegasen a su destinatario. ${ }^{85}$

Para entregar las cartas era habitual enviar emisarios, los cuales fueron especialmente útiles en los años anteriores a la guerra. El sargento Fernández de Bobadilla fue así enviado a la villa de Barcelos (río Negro) para comunicar el arribo de la comisión española de demarcación de límites. Poco después, los portugueses enviaron a Gabriel de Souza Filgueira en

80 Valerio Correa, Barcelos, 20 de mayo de 1763, APEP, códice 133, d. 13.

81 Extracto de los testimonios remitidos por Pestaña en carta de 20 de agosto de 1763, AGI, Lima, 1054.

82 Para un estudio sobre el conflicto en esta frontera, véase Castilho Pereira, 2017.

83 Melo e Castro a Siqueira Chaves, Pará, 25 de febrero de 1762, APEP, códice 83, d. 4.

84 Ataide Teive a Mendonça Furtado, Pará, 31 de julio de 1764, AHU, CU, 13, c. 57, d. 5153.

85 Francisco Rodrigues a Valério Correa, Cachoeira Grande, 14 de marzo de 1763, APEP, códice 133 , d. 2 . 
dirección contraria, para entregar una carta del gobernador de Grão-Pará al comisario español, José de Iturriaga ${ }^{86} \mathrm{Al}$ sur, el maestre de campo José Núñez llegó hasta Vila Bela de Mato Grosso para entregar a Rolim de Moura una carta del gobernador de Santa Cruz. ${ }^{87}$ Más banal fue la visita del padre Juan Rodríguez, «que pouco antes do rompimento, veyo aqui a titulo de dar-me as boas festas; mas na realidade ao que parece, a pesquisar o que por cá hia». ${ }^{88}$ Estos viajes tenían, lógicamente, una voluntad de reconocimiento de las posiciones rivales.

Además de estas visitas oficiales, ocurrían otros encuentros que permitían la creación y reproducción de relaciones personales entre soldados y oficiales de ambos bandos. Podemos rastrear estas relaciones en la correspondencia trocada por los oficiales de ambas coronas en los puestos más avanzados. En este tipo de cartas convivía la agencia individual de sus autores con el discurso oficial de las autoridades. Al comentar una de estas cartas, el gobernador de Rio Negro apuntaba que el sargento español hablaba «com alguna liverdade, e ahinda que se pode supor que hé propriamente sua, tão bem poderá ser influhida por seus mayores, e praticada por ele com disimulação». ${ }^{89}$ Dicho sargento era Fernández de Bobadilla, quien había entablado cierta relación con el ayudante portugués Francisco Rodrigues. La suya parece haber sido una relación de confianza, animada tanto por la necesidad de suministros como por el cálculo militar, puesto que la concordia era también una vía para burlar las defensas enemigas. Así, el capitán Felipe Sturm recibió órdenes para visitar el río Negro y dibujar un mapa del mismo, en el cual incluyó informaciones sobre la región controlada por los españoles tras cruzar la frontera disfrazado como un inofensivo pescador. ${ }^{90}$

Es por esa razón que las misivas intercambiadas por estos agentes contienen pasajes de relativa intimidad y evidencias de intercambios, pero también amenazas y bravuconadas. En diciembre de 1761, por ejemplo, Fernández de Bobadilla exigía el desalojo del raudal de Curucuy, haciendo responsables a los portugueses «de la sangre humana que se vertiere». ${ }^{91}$ d. 71 .

86 Melo e Povoas a Mendonça Furtado, Barcelos, 20 de agosto de 1760, AHU, CU, 20, c. 1,

87 Alonso Verdugo, 19 de noviembre de 1760, AGI, Charcas, 433; en Pastells, 1949, 738-749.

88 Rolim de Moura a Mendonça Furtado, Nossa Senhora da Conceição, 21 de julio de 1763, AHU, CU, 10, c. 12, d. 698 .

89 Valerio Correa al Gobernador, Barcelos, 26 de marzo de 1763, APEP, códice 133, d. 1. d. 4903 .

90 Melo e Castro a Mendonça Furtado, Pará, 12 de marzo de 1763, AHU, CU, 13, c. 54,

91 Fernández Bobadilla a Siqueira Chaves, San Carlos, 28 de diciembre de 1761, AHU, CU, 20, c. 2 , d. 111 . 
Meses después, las noticias de las guerras en Europa llegaron a aquella frontera para tensar todavía más la relación. La guerra le parecía probable al sargento español «por una noticia bolada que tuve», según la cual «el Rey de Portugal daba treinta millones a España porque hiciese paz con el Inglés, y no admitió». Aunque si hubiese guerra entre las coronas ibéricas, raro sería que les alcanzase en aquellas fronteras. Creía Bobadilla que «no habrá necesidad de que nuestro Monarca enviase tropa por este río, habiendo tan malos bastimentos, y pasos». La guerra más bien se resolvería en otros escenarios, como en el Pará, «y acaso sin saber nosotros nada». Desde el puesto de San Carlos tranquilizaba a su colega, asegurándole que, pasase lo que pasase, «no pretendo perder la amistad adquirida con vm». Y si Francisco Rodrigues «llegase hacer vasallo del Rey de España como puede suceder, y sucede cada día en otros Reinos, no perderá vm merced nada, y se aumentará nuestra amistad». ${ }^{92}$

\section{Indígenas: espías y mensajeros}

Otro tipo de correspondencia que atravesaba las fronteras estaba compuesto por las cartas escritas por prisioneros desde las posiciones enemigas, aunque esta resulta mucho más rara. Tras incendiar la misión de San Miguel en Mojos, los portugueses capturaron a los jesuitas Juan Rodríguez y Francisco Espí. Los misioneros presos «escribieron pidiendo se hiciese canje de ellos por los que ya estaban aquí», informando así de la situación a los españoles. ${ }^{93}$ Los prisioneros de guerra suponían también, obviamente, una fuente de información para sus captores. ${ }^{94}$ Cruzaban también la frontera los mensajes dirigidos a indígenas y soldados del bando enemigo, animándolos a la deserción. Así, los jesuitas de Mojos parecen haber escrito a los indígenas del lado portugués del Guaporé, advirtiéndoles de la llegada de una tropa de castigo y avisándoles que «fogissem eles para lá para não serem também castigados». ${ }^{95}$

92 Fernández Bobadilla a Francisco Rodrigues, San Carlos, 6 de marzo de 1763 (aunque con fecha de 1762), APEP, códice 133, d. 3.

93 Alonso Verdugo a Julián de Arriaga [?], 29 de diciembre de 1763, en Pastells, 1949, 990-995.

94 Juan de Pestaña a Julián de Arriaga, La Plata, 6 de marzo de 1764, en Pastells, 1949, 1018-1019.

95 Rolim de Moura a Mendonça Furtado, Nossa Senhora da Conceição, 30 de septiembre de 1762, AHU, CU, 10, c. 11, d. 679. 
Los indígenas, por su parte, no ignoraban las intenciones que escondían estas maniobras de los europeos y sabían que aquella guerra podía alterar sus vidas. El misionero Uriarte señaló que la noticia de la declaración de guerra «alborotó a todos los indios nuestros». De hecho, los misioneros procuraron «al principio ocultarlo a los indios, diciendo habían muerto los Reyes viejos y estos mozos ya no querían demarcaciones», pero el gobernador de Maynas, Antonio de Mena, «sobrecogido del susto, con motivo que iba a prevenir gente, se fue, como huyendo, y dijo a los indios que había guerra con los carayoas [portugueses], que se mantuviesen fuertes, que él iba a traer soldados castellanos que los defendiesen». Consternados por las noticias, los neófitos trataron de abandonar las misiones. Algunos jesuitas los animaron a ello, exagerando según Uriarte el peligro de una invasión, «como si el turco subiera ya por el Marañón, como por el Danubio a Viena el año pasado». ${ }^{96}$

Uriarte era de opinión contraria y consideraba improbable un ataque portugués, puesto que el Pará quedaba muy lejos, el botín sería miserable y, además, «harto harían con fortificarse contra la Cayana [Cayenne]». Misioneros y nativos, de todos modos, precisaban de informaciones más detalladas antes de tomar una decisión. A ese fin, varios indígenas partieron para recabar informaciones en el lado portugués. Los primeros en regresar «trajeron por respuesta que aún nada sabían de guerra los portugueses. Los segundos ya encontraron lo sabían, mas tenían orden de Pará de no hacer novedad con nosotros. Los terceros ya traían cartas que habían enviado soldados, que estuviesen a la defensiva no más, caso que los acometiesen los castellanos». Todavía unos cuartos trajeron noticias del misionero franciscano del Putumayo, que se ofrecía a enviar novedades cuando las hubiere desde su delicada posición de vanguardia. En la misión de Pebas tenía el padre «sus espías caumares, que daban cuenta de todo». ${ }^{97}$ Estas prevenciones, sin embargo, no impidieron que varias familias se refugiasen en el interior ante la posibilidad de un ataque portugués.

$\mathrm{Y}$ es que las comunidades indígenas, a pesar de haber accedido a reducirse en misiones, mantenían una espacialidad propia y contactos con las regiones interiores. ${ }^{98}$ Ello les permitía circular por los ríos y entregar noticias con rapidez. ${ }^{99}$ También les permitía atravesar las fronteras y hasta

96 Uriarte, 1986, 306-309.

97 Uriarte, 1986, 310-311.

98 Para la Amazonía portuguesa, Roller, 2014.

99 Domingos Franco al Gobernador, Borba, 3 de mayo de 1763, APEP, códice 130, d. 43. 
servir de mensajeros entre ambas coronas. ${ }^{100}$ En definitiva, contaban con un amplio margen de maniobra para zafarse de las amenazas de la guerra y para cambiar de bando en función de la coyuntura. Hay registros de fugas de familias y de aldeas enteras en aquellos años, lo que preocupaba a los europeos. ${ }^{101}$ La fijación de indígenas aliados cerca de los puestos de frontera resultaba fundamental y ello generó una competición por atraer a los nativos, percibidos como los «guardianes naturales de la frontera». ${ }^{102}$ Los portugueses del Guaporé, por ejemplo, trataban de seducir a los nativos con «cajones de medallas y abalorios», ofreciéndoles ropas para vestirse, «medallas y otras bujerías muy apetecibles de los indios para comprarles las comidas al mismo precio que los indios quieren». ${ }^{103}$

Aunque no es menos cierto que los nativos tenían sus propios motivos para desplazarse sin necesidad de recibir incentivos. Además de la guerra europea, existían otras esferas de interés político, religioso y militar que exigían la atención de cada comunidad indígena. Existía un universo de políticas internas que apenas conocemos y que se vieron afectadas por las pugnas ibéricas a lo largo del siglo XVIII. Los muras, por ejemplo, mantuvieron una agencia propia que incluía una gran movilidad y el hostigamiento a las canoas portuguesas. Otros grupos, como los ticunas o los manaos, que estaban sufriendo la arbitraria partición de sus territorios étnicos, activaron políticas diversas para mantener su posición en las nuevas fronteras europeas. Algo similar ocurrió con los aruás cerca de la desembocadura del río Amazonas, los cuales circularon entre la colonia francesa de Cayenne y el Pará, negociando sus alianzas en distintos contextos. ${ }^{104}$

Por otra parte, la capacidad de los indígenas de gestionar informaciones y rumores podía volverse en contra de los europeos, puesto que, en sus viajes por la región, a través de las invisibles fronteras imperiales, los grupos nativos podían pasar informaciones al enemigo, ya fuera por propia voluntad o a requerimiento ajeno. Así parece haber sucedido con un grupo de indígenas en la región del alto río Negro, los cuales regresaban de una estancia entre los castellanos, tal como observaba un oficial portugués: «e a mim me mete desconfiança do pouco tempo que prezestirão com os

100 Fernández Bobadilla a Francisco Rodrigues, San Carlos, 6 de marzo de 1763 (aunque con fecha de 1762), APEP, códice 133, d. 3.

101 Brito, 2016, 188-189, 206 y 211.

102 Meireles, 1989, 149. Domingues, 2000, 211-225.

103 Beingolea a Verdugo, San Pedro, 4 de octubre de 1763, AGI, Lima, 1054; en Pastells, 1949, 958-963.

104 Vidal, 1997; Zárate, 1998; Ibáñez-Bonillo, 2019. 
castilhanos, não haja aqui alguma pratica delles para lhe paçarem algumas notiçias dos nossos movimentos». ${ }^{105}$ Igualmente peligrosa era la circulación de noticias en los circuitos indígenas sobre los abusos cometidos por los portugueses. El vicario José Monteiro de Noronha, por ejemplo, recurrió a la fuerza para asegurar el descendimiento de unos indígenas. «Esta noticia correu pelo Japurá assima commonicada pelos Indios, aos outros que estão nas povoaçoens das nossas ditas caxoeyras, de sorte que se tem inquietado bastantemente». Temían los portugueses que los indígenas de aquella región tomasen «o partido castelhano» en aquella frontera. ${ }^{106}$

\section{Soldados y desertores}

La frontera era hogar también de fugitivos y otros espíritus errantes, como el flamenco Felipe Maneiro, que parecía ser «uno de aquellos seculares que por un revés o accidente adverso se destierran de sus patrias, y sin parar en países de comercio ni poblaciones grandes, se retiran a semejantes montañas desengañados del mundo». ${ }^{107}$ Estos personajes ayudaban también a la difusión de noticias sobre Europa y sobre el otro lado de la frontera. Finalizada la guerra, por ejemplo, un gascón que había llegado hasta Maynas informaba a los jesuitas castellanos sobre los planes franceses para la toma del Pará. ${ }^{108}$ Mestizos sin fortuna, negros libres y esclavos cimarrones circulaban también por las fronteras, sobre todo huyendo de Cayenne y de las minas brasileñas. En junio de 1763 se informaba que habían llegado a las misiones de Chiquitos «dos fugitivos de las tierras que habitaban los Portugueses el uno indiesito como de diez y siete años y el otro un negrillo de Angola como de veinte», los cuales eran «a propósito para guiar el ejército» español a las poblaciones de Matogrosso y Cuyabá, de donde procedían. ${ }^{109}$

Los soldados desertores circulaban también por aquellas fronteras, desde antes incluso de la guerra. ${ }^{110}$ Afectados por los retrasos en los pagos

105 Simão Coelho al Gobernador interino, Cachoeira Grande, 4 de julio de 1763, APEP, códice 133 , d. 26.

106 Pereira da Costa a Mendonça Furtado, Barcelos, 2 de septiembre de 1762, AHU, CU, 20, c. 2 , d. 112 .

107 Chantre y Herrera, 1901, 470

108 Uriarte, 1986, 311-312.

109 Resumen de una carta de Esteban Palosi a Alonso Verdugo, 13 de junio de 1763, AGI, Lima, 1054; en Pastells, 1949, 1010.

110 Nogueira, 2004. Lopes de Carvalho, 2014. 
de sus salarios, muchos sentían que «não há obrigação de servir ao Rey quando lhe não paga». ${ }^{11}$ Uno de los casos más espectaculares fue la deserción de trescientos soldados del río Negro, mencionado en la crónica del jesuita Uriarte. ${ }^{12}$ Tenemos otras noticias de soldados portugueses que huyeron al lado español de la frontera, ${ }^{113}$ donde tal vez usaron sus conocimientos como salvoconducto en el marco de la guerra. Uriarte se refiere a un cabo de escuadra que llegó a la misión de Omaguas, donde pidió «lo aviasen para arriba cuanto antes». Este traía una copia de la declaración de la guerra por Portugal y aseguraba que «estaban los de abajo en mucha necesidad, que no había gente y que los miserables soldados andaban descalzos y remendados por falta de providencia y pagas. Y si no fuera por el temor de los castigos, todos se huyeran a España». ${ }^{114}$

Este trasvase no suponía ninguna novedad y las misiones de Maynas, en cierta forma, funcionaron como espacios multinacionales donde convivían misioneros, indígenas, errantes y desertores. De la misma forma, indígenas huidos del lado español ofrecieron informaciones valiosas a los portugueses. ${ }^{115}$ El superior de las misiones de Mojos, Juan de Beingolea, escribía que los «portugueses son tan astutos, que logrando algún desertor lo tratarán con estimación y les pagarán bien, por la utilidad que experimentarán en ellos». Los desertores podían actuar como «ladrones de vacas» y «robar las caballerías y atajos de yeguas» de las misiones; ${ }^{116} \mathrm{y}$, claro, también como informantes. Sin embargo, los desertores eran un arma de doble filo, ya que siempre podían arrepentirse de su deserción. Es lo que ocurrió con Alexandre Ferreira, que escribió al gobernador de Mato Grosso pidiendo perdón por su fuga y comunicando informaciones sobre los españoles. ${ }^{117}$

Los desertores y otros viajeros, por otra parte, también podían informar a sus propias autoridades cuando no abandonaban los límites imperiales. Al retirarse de la frontera y tratar de difuminarse en la retaguardia

\footnotetext{
112 Uriarte, 1986, 241-245. Gómez González, 2014, 250-252.

113 Joaquim Tinoco Valente al Gobernador, Barcelos, 6 de septiembre de 1764, APEP, códice 133, d. 94.

114 Uriarte, 1986, 312.

115 Felipe Sturm al Gobernador, Cachoeira Grande, 4 de julio de 1763, APEP, códice 133, d. 25 .

116 Beingolea a Verdugo, San Pedro, 4 de octubre de 1763, AGI, Lima, 1054; en Pastells, 1949, 958-963.

117 Traducción de la carta de A. Ferreira a Rolim de Moura, 13 de junio de 1761, AGI, Charcas, 433 .
} d. 75 .

111 Joaquim Tinoco Valente al Gobernador, Barcelos, 28 de julio de 1764, APEP, códice 133, 
colonial, los indígenas y soldados llevaban con ellos una carga informativa de incierta utilidad. Joaquim de Mattos, junto con dos indígenas, abandonó el río Guaporé y al llegar al Amazonas dio noticias sobre los últimos movimientos en la frontera de Mojos. ${ }^{118}$ Sin embargo, se sospechó entonces que «para que não lhe embaraçasse a fuga», tuvo que convencer al soldado José Pedro Gayo «que tudo ficava perdido». ${ }^{119}$ Los desertores suponían, así, un vector de desinformación que podía propagar el desánimo entre las tropas y la población. Quizás por ello, las autoridades españolas se mostraron inflexibles con los desertores. Capturados dos de ellos, fueron puestos en consejo y «fue condenado a ser pasado por las armas al que le tocase la suerte, como se executó en el que le cayó». ${ }^{120}$

$\mathrm{Y}$ es que, como es lógico, las noticias que circularon aquellos días por la frontera no siempre se correspondían con la realidad. Regresando de su visita a las regiones interiores del obispado de Pará, el obispo João de São José, «desejando novas de Portugal», se informó en Gurupá a través de un soldado que venía de Belém. El soldado «contou tantas felicidades, que nos assombraram, accrescentando que toda a Hespanha estava excommungada, por não ter pedido o Rei Catholico licença ao Papa para fazer guerra a Portugal». ${ }^{121} \mathrm{La}$ expectación generada por la guerra propiciaba exageraciones, también entre las poblaciones indígenas. ${ }^{122}$ Cierto día un indígena informó al padre Uriarte sobre ruidos de tambores en el río que anunciaban la llegada de una tropa portuguesa. El rumor generó pánico en la misión, aunque pronto fue disipado al achacar el ruido a «las gamitanas, que se amontonan en esa laguna para desovar». De esta forma, «el temor se redujo a chasco y risa». El misionero remata la anécdota con una frase que bien podría resumir cómo se vivió en las fronteras amazónicas aquella guerra entre las dos potencias europeas: «Así lo fuimos pasando, entre sustos y alegrías». ${ }^{123}$ d. 26 .

118 Domingos Franco para el Gobernador, Borba, 15 de mayo de 1763, APEP, códice 128,

119 Rolim de Moura al Gobernador, Nossa Senhora da Conceição, 28 de abril de 1763, AHU, CU, 13, c. 54, d. 4953. Rolim de Moura al Gobernador, Conceição, 15 de agosto de 1763, APEP, códice 129, d. 79.

120 Alonso Verdugo a Julián de Arriaga, 22 de diciembre de 1763, Santa Cruz, AGI, Lima, 1054 .

121 Queirós, 1847, 364-365.

122 Para la importancia de los rumores en otra situación de frontera, Dowd, 1996.

123 Uriarte, 1986, 313-314. 


\section{Conclusiones}

La circulación de noticias sobre la guerra y el intercambio de informaciones relacionadas con ella han servido para demostrar en las páginas anteriores la conexión de las fronteras amazónicas con un acontecimiento global que implicó a las principales potencias de la época. Lejos de permanecer aisladas en un plano de irrelevancia geopolítica, las regiones de frontera presentadas en este texto jugaron su papel en dicho conflicto. ${ }^{124}$ Consecuentemente, los habitantes de las regiones amazónicas se han mostrado en los ejemplos anteriores como sujetos activos en la circulación de informaciones, desplegando estrategias comunicativas complejas y mostrando un claro interés por conocer novedades sobre la guerra. ${ }^{125}$ Todavía, la transmisión de noticias a través de las fronteras políticas, tal y como se ha mostrado en este artículo, demuestra la porosidad de estos límites y la flexibilidad de los agentes para transitar por ellos. ${ }^{126}$

Todo ello reivindica el lugar de la Amazonía en el estudio de la Guerra Fantástica. Sin embargo, su vinculación con los procesos globales no debe ocultar los ritmos particulares de las fronteras americanas. La dificultad de las comunicaciones con la península dilataba la llegada de informaciones y ello generó una temporalidad propia en el interior americano. Además, los únicos encontronazos ocurrieron cuando ya se habían firmado las paces en Europa. Eso hizo que la información sobre la guerra europea «caducase» en su cruce del océano y que las órdenes y noticias tuvieran siempre un asterisco de desfase temporal que lastraba su credibilidad. Además, «el carácter discontinuo y aleatorio» de la información, «generaba dudas sobre su certidumbre». ${ }^{127}$ En su tránsito americano, las noticias se transformaban y en esas alteraciones se pueden percibir las agencias de distintos actores, ${ }^{128}$ como virreyes, gobernadores, misioneros o soldados. Recordando aquellos días, el padre Uriarte comentaba la abundancia de noticias falsas que llegaron hasta Maynas. ${ }^{129}$

Las dudas sobre su veracidad, sin embargo, no mermaban la capacidad de estas noticias para insuflar ánimos. El fracaso de la invasión española en la península y el resultado final de la contienda, por ejemplo, animaron a

124 Brito, 2018.

125 Earle, 1997, 184. Olivari, 2014.

126 Gómez González, 2014.

127 González Cruz, 2019a, 174.

128 Devivo, 2019.

129 Uriarte, 1986, 314. 
los habitantes de la Amazonía lusa en pleno conflicto y no habrían de ser raras expresiones como las del oficial Ignacio de Castro, quien se animaba ante una posible invasión española por el río Madeira: «assim como fomos vitoriozos em Portugal», aquí también lo habrían de ser, «pois a espada da rezão tem muito vigor». ${ }^{130}$ Las opiniones de este estilo estaban influenciadas por los discursos oficiales emitidos en forma de bandos y gacetas, pero también por el suministro de noticias a través de correspondencias escritas y la dispersión oral de noticias y rumores. En general, las informaciones sobre la guerra europea analizadas en este artículo aparecen alineadas con los intereses de las respectivas coronas. Son escasos los indicios que hemos encontrado de información crítica o derrotista en las fronteras, lo cual obviamente no significa que esta no existiera.

Las informaciones escritas, por otra parte, servían para el consumo de un sector limitado de la sociedad de frontera. Si bien es cierto que las cartas y gacetas podían ser leídas en voz alta para públicos mayores, los lectores de noticias se limitaban a ciertos grupos como religiosos, administradores reales, oficiales y comerciantes. Hemos visto en este texto cómo las órdenes religiosas, y concretamente la Compañía de Jesús, consolidaron un espacio informativo propio que les permitía generar sus propios discursos. Esa habilidad provocaba temores en ambas coronas, que no querían la participación de un tercer actor en sus fronteras. En cuanto a la élite administrativa, compuesta por gobernadores, capitanes y presidentes, se limitaron a reproducir las noticias oficiales que recibían y a mantener la lealtad a sus soberanos, incluso en el plano opinativo.

Similares posibilidades deben ser consideradas para el grueso de la sociedad (soldados, indígenas, africanos), el cual se informó de la guerra a través de canales orales por los que era sencillo que fluyesen otras voces y otras informaciones distintas a la narrativa oficial. A pesar de ello, hemos visto cómo los súbditos, por lo menos en sus expresiones escritas para uso oficial, se mantuvieron fieles al espíritu de sus respectivas coronas. Más agencia es posible detectar en su sociabilidad de frontera, donde la información podía ser utilizada como herramienta en el juego político. Hemos visto algunos ejemplos en los que dichas informaciones se usaron para desinformar o desanimar al enemigo. Sin embargo, el recurso más habitual parece haber estado ligado a la propia supervivencia o promoción personal de los d. 25 .

130 Ignacio de Castro para el Gobernador, Barcelos, 15 de mayo de 1763, APEP, códice 128, 
actores locales. Para ese fin, de vital importancia resultaron informaciones sobre los planes del enemigo o el estado de sus tropas. La información local, en ese sentido, jugó un papel tan decisivo como las grandes informaciones de alcance global.

Recibido, 22 de noviembre de 2020 Segunda versión, 11 de mayo de 2021 Aceptado, 24 de junio de 2021

\section{Referencias Bibliográficas}

Amat y Junient, Manuel, Memoria de Gobierno, edición de Vicente Rodríguez Casado y Florentino Pérez-Embid, Sevilla, Escuela de Estudios Hispano-Americanos, 1947.

Barrento, António, Guerra Fantástica 1762: Portugal, o Conde de Lippe e a Guerra dos Sete Anos, Lisboa, Tribuna, 2006.

Bastos, Carlos Augusto, No limiar dos Impérios. A fronteira entre a capitania do Rio Negro e a Província de Maynas: Projetos, Circulações e Experiências (c. 1780-c. 1820), São Paulo, HUCITEC Editora, 2017.

Bouza, Fernando, Imagen y propaganda. Capítulos de historia cultural del reinado de Felipe II, Madrid, Akal, 1998.

Boccara, Guillaume, «Génesis y estructura de los complejos fronterizos euro-indígenas. repensando los márgenes americanos a partir (y más allá) de la obra de Nathan Wachtel», Memoria Americana. Cuadernos de Etnohistoria, 13, Buenos Aires, 2005, 21-52.

Brito, Adilson, «Insubordinados sertões. O Impêrio portugués entre guerras e fronteiras no norte da América do Sul - Estado do Grão-Pará, 1750-1820», tesis doctoral dirigida por João Paulo Garrido Pimenta, São Paulo, Universidade de São Paulo, Faculdade de Filosofia, Letras e Ciências Humanas, 2016. Disponible en: https://teses.usp.br/teses/disponiveis/8/8138/tde-10112016135356/pt-br.php [Consultado: 02/03/2021].

Brito, Adilson, «Guerra, fiscalidade e dinâmicas transfronteiriças no vale ibero-americano do Alto Amazonas, 1763-c.1772», en Brito, Adilson y Bastos, Carlos (eds.), Entre extremos: experiências fronteiriças e transfronteiriças nas regiões do Rio Amazonas e do Rio da Prata - América Latina, Séculos XVI-XX, Curitiba, CRV Editora, 2018, 105-148.

Castilho Pereira, Ione Aparecida Martins, «Guerra nas missões de Mojos: uma análise do conflito luso-espanhol pela posse da antiga missão jesuítica de Santa Rosa de Mojos no rio Guaporé (1760-1764)», Memoria Americana. Cuadernos de Etnohistoria, 25:2, Buenos Aires, 2017, 95-112. 
Chantre y Herrera, José, Historia de las Misiones de la Compañía de Jesús en el Marañón español, Madrid, Imprenta de A. Avrial, 1901.

Devivo, Filippo, «Microhistories of Long-Distance Information: Space, Movement and Agency in the Early Modern News», Past and Present, 242:14, Oxford, 2019, 179-214.

Domingues, Ângela, Quando os índios eram vassalos: colonização e relações de poder no norte do Brasil na segunda metade do século XVIII, Lisboa, Comissão Nacional para as Comemorações dos Descobrimentos Portugueses, 2000.

Dowd, Gregory Evans, «The Panic of 1751: The Significance of Rumors on the South Carolina-Cherokee Frontier», The William and Mary Quarterly, 53:3, Williamsburg (Virginia), 1996, 527-560.

Durand, José (comp. y prólogo), Gaceta de Lima de 1756 a 1762. De Superunda a Amat, Lima, Corporación Financiera de Desarrollo/Oficina de Asuntos Culturales, 1982a.

Durand, José (comp. y prólogo), Gaceta de Lima de 1762 a 1765. Apogeo de Amat, Lima, Corporación Financiera de Desarrollo/Oficina de Asuntos Culturales, 1982b.

Earle, Rebecca, «Information and Disinformation in Late Colonial New Granada», The Americas, 54:2, 1997, 167-184.

Elexpuru, Antonio de, Compendio de las prevenciones, que el excelentissimo señor don Manuel de Amat y Junient [...] hizo para la defensa de la guerra contra Portugal, è Inglaterra, 1763.

Erbig Jr., Jeffrey Alan, Where Caciques and Mapmakers Met: Border Making in Eighteenth-Century South America, Chapel Hill, University of North Carolina Press, 2020.

Espejo Cala, Carmen, «La circulación de las noticias en España a finales del siglo XVI. Relaciones de sucesos de Rodrigo de Cabrera (1595-1600) sobre las guerras turcas», Estudios sobre el Mensaje Periodístico, 21:1, Madrid, 2015, 89-103.

García Arenas, Mar, «Un Tajo conquistado por la Casa de Borbón. Guerra y propaganda política francesa sobre la Guerra de los Siete Años», en Diez del Corral, Pilar (coord.), A donde Neptuno reina: Water, Gods and Power during the Modern Era (16th-18th Centuries), Lisboa, CHAM, 2020, 59-76.

Gil, Juan, Mitos y Utopías del Descubrimiento. III: El Dorado, Madrid, Alianza Editorial, 1989.

Gómez González, Sebastián, Frontera selvática. Españoles, portugueses y su disputa por el noroccidente amazónico, siglo XVIII, Bogotá, Instituto Colombiano de Antropología e Historia, 2014.

González Cruz, David, «Propaganda y fuentes de información en la prensa periódica de la américa hispana durante las guerras del siglo XVIII», Obradoiro de Historia Moderna, 20, Santiago de Compostela, 2011, 355-384. 
González Cruz, David, «La circulación de la información entre España y América en los períodos de guerra del siglo XVIII», en Melón Jiménez, Miguel Ángel et. al. (eds.), Dinámicas de las fronteras en periodos de conflicto. El Imperio español (1640-1815), Cáceres, Universidad de Extremadura, 2019a, 173-193.

González Cruz, David, «Paz anunciada: Publicidad y estrategia de comunicación en España y la América hispana durante el siglo XVIII», en Martínez Shaw, Carlos (coord.), Una vida dedicada a la universidad: Estudios en homenaje al profesor José Manuel de Bernardo Aires, Córdoba, Editorial Universidad de Córdoba, 2019b, 499-520.

Habermas, Jürgen, Historia y crítica de la opinión pública, Barcelona, Editorial Gustavo Gili, 1981 [1. ${ }^{a}$ ed. 1962].

Herzog, Tamar, «La Gaceta de Lima (1756-1761): la reestructuración de la realidad y sus funciones», Histórica, 16:1, Lima, 1992, 33-61.

Herzog, Tamar, Fronteras de posesión. España y Portugal en Europa y las Américas, Madrid, Fondo de Cultura Económica/Red Columnaria, 2018.

Ibáñez-Bonillo, Pablo, «Aruás en los primeros tiempos del Directorio: Frontera, trabajo y poder en la desembocadura del Amazonas (1757-1767)», Revista de História, 178, São Paulo, 2019, 1-33.

Langfur, Hal, The Forbidden Lands. Colonial Identity, Frontier Violence, and the Persistence of Brazil's Eastern Indians, 1750-1830, Stanford, Stanford University Press, 2006.

Levin Rojo, Danna A. y Radding, Cynthia, The Oxford Handbook of Borderlands of the Iberian World, New York, Oxford University Press, 2019.

Lopes de Carvalho, Francismar-Alex, Lealdades negociadas. Povos indígenas e a expansão dos impérios ibéricos nas regiões centrais da América do Sul (segunda metade do século XVIII), São Paulo, Alameda, 2014.

Lucena Giraldo, Manuel, Laboratorio Tropical. La expedición de límites al Orinoco, 1750-1767, Caracas, Monte Ávila Editores/CSIC, 1991.

Marchena, Juan, Los buques de la Real Armada. 1700-1825, tomo II, en Marchena, Juan y Cuño, Justo (eds.), Vientos de guerra. Apogeo y crisis de la Real Armada. 1750-1823, Madrid, Ediciones Doce Calles, 2018.

Meireles, Denise Maldi, Guardiães da Fronteira. Rio Guaporé, século XVIII, Petrópolis, Vozes, 1989.

Melón Jiménez, Miguel Ángel, «Un juego diplomático plagado de incertidumbres. Las negociaciones que precedieron al comienzo y al final de la guerra entre España y Portugal (1762-1763)», Vegueta, 16, Las Palmas de Gran Canaria, 2016, 195-220.

Mendonça, Marcos Carneiro, A Amazônia na era Pombalina, tomo III, Brasilia, Edições do Senado Federal, 2005.

Negro, Sandra, «Destierro, desconsuelo y nostalgia en la crónica del P. Manuel Uriarte, misionero de Maynas (1750-1767)», Apuntes, 20:1, Bogotá, 2007, 92-107. 


\section{PABLO IBÁÑEZ-BONILLO}

Nogueira, Shirley Maria Silva, «"Esses miseráveis delinquentes”: desertores no Grão-Pará setecentista» en Castro, Celso; Izecksohn, Vitor y Kraay, Hendrik (eds.), Nova história militar brasileira, Río de Janeiro, FGV Editora, 2004, 87-109.

Olivari, Michele, Avisos, pasquines y rumores. Los comienzos de la opinión pública en la España del siglo XVII, Madrid, Cátedra, 2014.

Pastells, Pablo, Historia de la Compañía de Jesús en la Provincia del Paraguay, tomo VIII, segunda parte, Madrid, CSIC, 1949.

Perera, Miguel Ángel, «La expedición de límites de 1750 en la Guayana española: los logros de una tarea que nunca comenzó», Procesos. Revista Ecuatoriana de Historia, 41, Quito, 2015, 35-61.

Queirós, João de São José, "Viagem e visita do sertão em o bispado do Gram Pará em 1762 e 1763”, Revista Trimensal de História e Geographia, Segunda Serie, Tomo II, Rio de Janeiro, 1847, 43-107, 179-227, 328-375, 476-527.

Ramos Pérez, Demetrio, El Tratado de límites de 1750 y la expedición de Iturriaga al Orinoco, Madrid, CSIC, 1946.

Roller, Heather F., Amazonian Routes. Indigenous Mobility and Colonial Communities in Northern Brazil, Stanford, Stanford University Press, 2014.

Santos, Fabiano Vilaça dos, «Uma vida dedicada ao Real Serviço. João Pereira Caldas, dos sertões do Rio Negro à nomeação para o Conselho Ultramarino (1753-1790)», Varia Historia, 26:44, Belo Horizonte, 2010, 499-521.

Speelman, Patrick J., «Strategic Illusions and the Iberian War of 1762», en Danley, Mark H. y Speelman, Patrick J. (eds.), The Seven Years' War. Global Views, Leiden/Boston, Brill, 2012, 429-460.

Téllez Alarcia, Diego, «España y la Guerra de los Siete Años», en Porres Marijuán, María Rosario y Reguera, Iñaki (eds.), La proyección de la Monarquía Hispánica en Europa: política, guerra y diplomacia entre los siglos XVI y XVIII, Bilbao, Servicio Editorial de la Universidad del País Vasco, 2009, 197-230.

Uriarte, Manuel J., Diario de un misionero de Maynas, Iquitos, IIAP/CETA, 1986.

Vidal, Silvia, «Liderazgo y confederaciones multiétnicas amerindias en la amazonia luso-hispana del siglo XVIII», Antropológica, Caracas, 87, 1997, 19-46.

Zárate, Carlos, «Movilidad y permanencia ticuna en la frontera amazónica colonial del siglo XVIII», Journal de la Société des Américanistes, París, 84:1, 1998, 73-98. 